\title{
Application of Central Composite Design to the Photo Fenton Degradation of Methyl Orange Azo Dye Using Fe-Activated Carbon Catalyst
}

\author{
Abubakar Muhammad \\ Department of Pure and Industrial Chemistry \\ Umaru Musa Yar'adua University \\ Katsina, Nigeria
}

\author{
Ahmed Lawal Mashi \\ Department of Pure and Industrial Chemistry \\ Umaru Musa Yar'adua University \\ Katsina, Nigeria
}

\begin{abstract}
Photo-fenton oxidation technique is one of the emerging oxidation processes explored in treatment of organic pollutants in aqueous solutions. This research is focused on utilization of $\mathrm{Fe}$ (II) loaded activated carbon and $\mathrm{H}_{2} \mathrm{O}_{2}$ (aq) in a photofenton process to generate hydroxyl radicals that mineralize methyl orange dyes. Samples of activated carbon were treated with $\mathrm{Fe}\left(\mathrm{NO}_{3}\right)_{2(\mathrm{aq})}$ and characterized using $\mathrm{SEM}$, pHzPC, specific surface area and boehm's titration. The degradation of methyl orange by the iron loaded activated carbon (Fe-Ac), via photo-Fenton process, was investigated in lab-scale defined by experimental design. Central composite design (CCD) was used to evaluate the effects of the five independent variables considered for the optimization of the oxidative process: time, $\mathrm{Fe}$ Ac dose, methyl orange concentration, $\mathrm{pH}$ and $\mathrm{H}_{2} \mathrm{O}_{2}$ concentrations. In the optimization, the correlation coefficients $\left(R^{2}\right)$ for the quadratic model was 0.9941 . Optimum reaction conditions were obtained at $\mathbf{p H}=3$, catalyst dose $=0.1 \mathrm{mg} / 100 \mathrm{ml}, \mathrm{H}_{2} \mathrm{O}_{2}=0.62 \mathrm{ml}$, methyl orange concentration $=5 \mathrm{mg} / \mathrm{l}$ and time $=30$ minutes.
\end{abstract}

Keywords:- Photofenton, Photodegradation, Methyl Orange.

\section{INTRODUCTION}

Removal of dyes from wastewater is one of the main problems encountered in the textile and other industries. Color is mainly caused by colorants that blocks light and penetrate into water bodies to induce toxicity. Therefore it is required that colored effluents be treated before the effluents are discharged into an aquatic environment [1]. Advance Oxidation Processes (AOPs) such as Fenton and photoFenton like processes are being widely developed for effective treatment of textile and other industrial effluents [2].

Some efforts concerned with modification of the photo-Fenton catalysts with some supports have been reported. The supports can minimize the cost of the process due to the reusability properties, and also improve the activity, stability and selectivity of the catalyst [3]. A wide range of solid materials, such as silica, zeolites, and pillared clays, have been reported to be active in oxidative degradation of organic compounds through the photoFenton-like reaction [4]. Some minerals such as hematite, goethite, and vermiculite and also activated carbon were reported to be loaded with Fenton catalyst to give more effective oxidation process [5]. In the photo-Fenton-like process, the combination of $\mathrm{Fe}^{3+}$ with Activated carbon is an alternative process that can be operated in an effective, easy to control and cost-efficient manner [6]. This offers an interesting advantage for its application on an industrial scale; that is, the supported photocatalysts can be reused. As investigated in previous works, the reuse of supported catalysts is in line with the synergistic effect of the adsorptive properties of catalyst support [7].

Mutagenic azo dyes such as methyl orange (MO) can accumulate in bodies of water and sediments to a level considered significantly toxic to the environment. A research performed by Umbuzeiro et al [8] in the Salmonella/Microsome test, showed a low to moderate mutagenic activity in Cristais River (Cajamar/SP), due to the presence of azo dyes, nitroaromatic compounds and aromatic amines. The study detected the presence of dyes in all the samples collected (effluent of the dyeing industry, raw water and water treatment station), and associated the mutagenicity of these samples mainly of the raw water with the presence of dyes and colorless polycyclic nitroaromatic compounds, possibly generated during the treatment of the effluent. Oliviera [9] also showed the presence of components of the black commercial dye (BDCP) and aromatic amines in the raw and treated effluents discharged by a dyeing industry, indicating that the industrial treatment was not efficient for the removal of these compounds, which corroborated some studies performed by Lise [10], showing that activated sludge systems were not efficient in the removal of azo dyes present in industrial effluents.

Maguire and Tkacz [11] detected 15 different dyes in samples of water, suspended solids and sediments of a river of Canada, and 3 of which were identified as: C.I. Disperse Blue 79, C.I. Disperse Blue 26 and C.I. Disperse Red 60. Oliveira [9] showed that the presence of about $1 \mu \mathrm{g}$ of C.I. Disperse Blue 373 and $10 \mu \mathrm{g}$ C.I. Disperse Orange 37, for each $1 \mathrm{~g}$ of the sediment of two distinct environmental samples (one located immediately below the discharge of the effluent of a textile industry and the other from a collection site situated at the entrance of the water treatment station for public supply), which characterizes high rates of mutagenic activity for these two samples. These same dyes were detected in water samples in the same area analyzed by Umbuzeiro [12]. 
In this paper, we investigated the degradation of methyl orange dye in aqueous solution using previously unreported catalyst prepared by immobilizing $\mathrm{Fe}$ (III) on activated carbon support. Response surface methodology (RSM) was employed to generate 50 runs of experiments that ultimately provided the statistical data presented in this report. The variables studied are: reaction time, Fe-Ac dose, methyl orange concentration, $\mathrm{pH}$ and $\mathrm{H}_{2} \mathrm{O}_{2}$ concentrations.

\section{METHODOLOGY}

Fresh samples of activated carbon (Sigma Aldrich) were used without further purification. The Fe-Ac photoFenton catalyst was prepared according to the procedure reported by Fatima et al [13]. Samples of Activated carbon were dispersed in a mixture with $\mathrm{Fe}\left(\mathrm{NO}_{3}\right)_{2}$ (Mayer and Baker) solution followed by stirring for $24 \mathrm{~h}$. The concentration of $\mathrm{Fe}$ (II) used was 5 times the cation exchange capacity (CEC) of Activated carbon $\left(4 \mathrm{mmolg}^{-1}\right)$. The suspension was then filtered and oven dried at $60{ }^{\circ} \mathrm{C}$ for $2 \mathrm{~h}$. The surface morphology of the catalyst was characterized using Scanning electron microscopy (SEM). Catalyst surface area, Cation exchange capacity, $\mathrm{pH}$ of zero point charge $\left(\mathrm{pH}_{\mathrm{zpc}}\right)$ and surface acidic functional groups are also reported.

The photodegradation experiments were performed in a lab-scale using a $500 \mathrm{~W}$ halogen lamp as irradiation source. The reaction setup consists of conical flasks set containing the dye solution and catalyst mounted on an electric shaker stationed $1 \mathrm{~m}$ away from the light source. For tests using only the Fenton reagent, the experiment was kept away from light by covering it with aluminium foil. The flasks containing stated amount of reagents are mounted on the shaker with light turned on and shaked for the stated time after which the absorbance of the dye left is measured using UV/Visible spectrophotometer.

\section{RESULTS}

\section{A. Characterization of Fe-Ac Photocatalyst}

The Scanning Electron micrographs of pure activated carbon and Fe-Ac are shown in Fig.1. Both images display irregular cracks and crevices on the surface which could be attributed to the amorphous and heterogeneous nature of activated carbon. Fig.1a shows small pores on the surface and reveals sheet-like structures with troughs and crests in a synchronized manner. The pores are more evident in Fig. 1b which displays a rather eroded surface. This change in morphology could be attributed to treatment with $\mathrm{Fe}$
$\left(\mathrm{NO}_{3}\right)_{2(\mathrm{aq})}$ and perhaps agitation during preparation of the photocatalysts.

Experimental results of $\mathrm{pH}_{\mathrm{ZPC}}$ determination, is shown in Fig.2. As evident, change in $\mathrm{pH}$ by activated carbon $(\Delta \mathrm{pH})$ was plotted against initial $\mathrm{pH}\left(\mathrm{pH}_{\mathrm{o}}\right)$ of the solution having constant ionic strength $\left(0.01 \mathrm{M} \mathrm{NaNO}_{3}\right)$. The $\mathrm{pH}$ at a point where the initial $\mathrm{pH}$ of the solution intersects the $(\Delta \mathrm{pH})$ equilibrated by a certain amount of an material is referred to as the $\mathrm{pH}_{\mathrm{ZPC}}$ [14]. The effect of $\mathrm{pH}$ was tested to evaluate the feasibility of Fe (II) loading. The value of $\mathrm{pH}_{\mathrm{ZPC}}$ obtained was (7.95). It has been reported that the $\mathrm{pH}$ of carbon ranging between 4 and 8 is acceptable for most of the applications [15]. This value of $\mathrm{pH}_{\mathrm{ZPC}}$ (7.95) suggests that the surface becomes positive at $\mathrm{pH}$ values less than 7.95 and becomes negative at $\mathrm{pH}$ values above 7.95. It thus indicates that below the $\mathrm{pH}$ of 7.95 loading of $\mathrm{Fe}$ (II) via cation exchange could rapidly takes place. a.

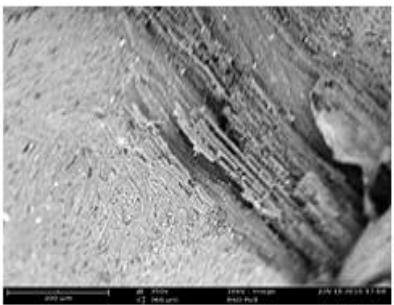

b.

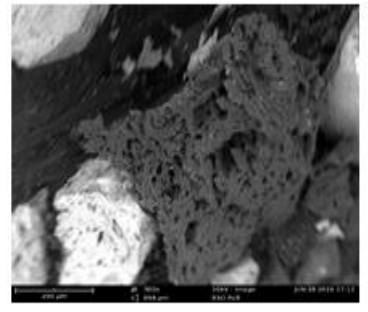

tivated Carbon
The Sear's specific surface area of the activated carbon sample is $433 \mathrm{~m}^{2} \mathrm{~g}^{-1}$ (Table 1). This is expected considering that a single gram of activated carbon can have a surface area in excess of $500\left(\underline{\mathrm{m}}^{2} \mathrm{~g}^{-1}\right)$, with $1500 \underline{\mathrm{m}}^{2} \mathrm{~g}^{-1}$ being readily achievable.

\begin{tabular}{|c|c|}
\hline Parameter & Value \\
\hline $\mathrm{pH}_{\mathrm{ZPC}}$ & 7.95 \\
\hline Sears surface area & $433 \mathrm{~m}^{2} \mathrm{~g}^{-1}$ \\
\hline Cation exchange capacity & $4 \mathrm{mmolg}^{-1}$ \\
\hline
\end{tabular}

Table 1:- Physico-chemical parameters of Fe-Ac catalyst

CEC is the total capacity of a solid substance to hold exchangeable cations. The CEC value obtained for the activated carbon is $4 \mathrm{mmolg}^{-1}$ (Table 1). This result is comparable to $4.67 \mathrm{mmolg}^{-1}$ obtained by Kavitha [14]. The $\mathrm{CEC}$ value signifies the equilibrium amount of $\mathrm{Fe}$ (II) that can be loaded on to the activated carbon surface [16]. 
ISSN No:-2456-2165

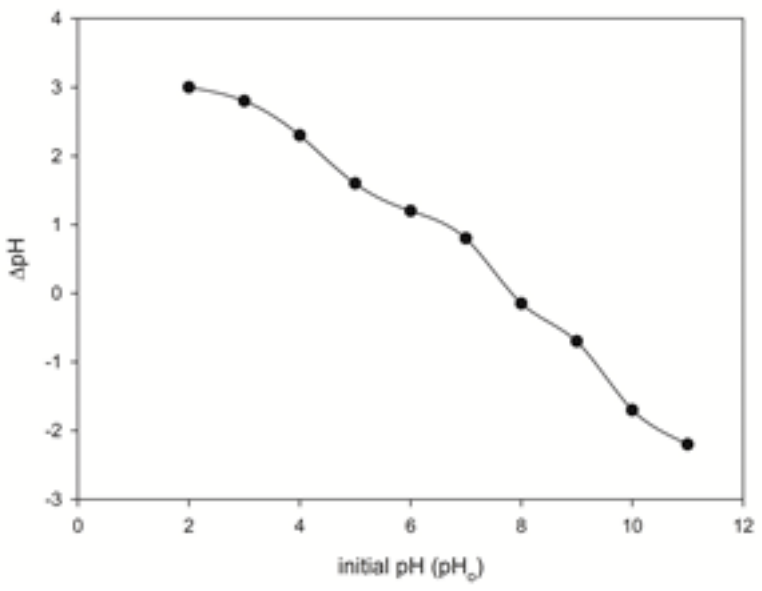

Fig 2:- $\mathrm{pH}_{\mathrm{ZPC}}$ of Activated carbon

Table 2 displays the result of Boehm's titration. The presence of acidic groups namely Lactonic, Phenolic and carboxylic is evident. Concentration of the surface groups (meq/g) obtained is in the order Phenolic (1.021) > Carboxylic (0.28) > Lactonic (0.023). The results are in agreement with $1.0,0.3$ and 0.03 for Phenolic, carboxylic and Lactonic respectively reported by Edwin [17].

\begin{tabular}{|c|c|}
\hline Surface Groups & Concentration $\mathbf{( m e q} / \mathbf{g})$ \\
\hline Lactonic & 0.023 \\
\hline Phenolic & 1.021 \\
\hline Carboxylic & 0.28 \\
\hline Total & 1.342 \\
\hline
\end{tabular}

Table 2:- Results of Boehm's titration

\section{B. Photo-Fenton Degradation of Methyl Orange}

\section{Control Experiment}

The results of control preliminary experiment Fig.3 shows the profile of MO reduction by varied methods: Photo-Fenton (illumination with $\mathrm{Fe}-\mathrm{Ac}$ catalyst and hydrogen peroxide), Fenton (Fe-Ac and hydrogen peroxide without light), Adsorption (Fe-Ac without light and hydrogen peroxide) and Photolysis (without Fe-Ac, light and hydrogen peroxide) under identical conditions. The experimental results presented in Fig. 3 is in the order PhotoFenton $>$ Fenton $>$ Adsorption $>$ Photolysis. There is a very significant difference in $\mathrm{MO}$ dye removal between photoFenton (75\%) and Fenton (44\%). This is explained by the increased generation of hydroxyl radicals by incident light in photo-Fenton system [2]. Similarly, Adsorption (12.5\%) is less than Fenton (44\%) due to lack of hydroxyl radicals to initiate photodegradation [18]. Lastly photolysis (0.6\%) removal is attributed to slight MO dye instability in the presence of light. Therefore it can be concluded that in photodegradation process, the observed MO dye removal has elements of photolysis, adsorption, Fenton and photoFenton processes.

\begin{tabular}{|c|c|c|c|c|c|c|}
\hline \multicolumn{7}{|c|}{ Sequential Model Sum of Squares } \\
\hline Source & Sum of squares & $\begin{array}{c}\text { Degree of } \\
\text { Freedom }\end{array}$ & $\begin{array}{c}\text { Mean } \\
\text { Square }\end{array}$ & F Value & Prob $>F$ & \\
\hline Mean & 183860.48 & 1 & 183860.5 & & & \\
\hline Linear & 5604.15 & 5 & 1120.83 & 18.27 & $<0.0001$ & \\
\hline 2FI & 12 & 10 & 1.2 & 0.02 & 1.0000 & \\
\hline Quadratic & 2638.77 & 5 & 527.75 & 314.87 & $<0.0001$ & Suggested \\
\hline Cubic & 21.35 & 15 & 1.42 & 0.73 & 0.7229 & Aliased \\
\hline Residual & 27.25 & 14 & 1.95 & & & \\
\hline Total & 192164 & 50 & 3843.28 & & & \\
\hline
\end{tabular}

Table 3:- Predicted Models for photo-Fenton oxidation of $\mathrm{MO}$ using Fe-Ac

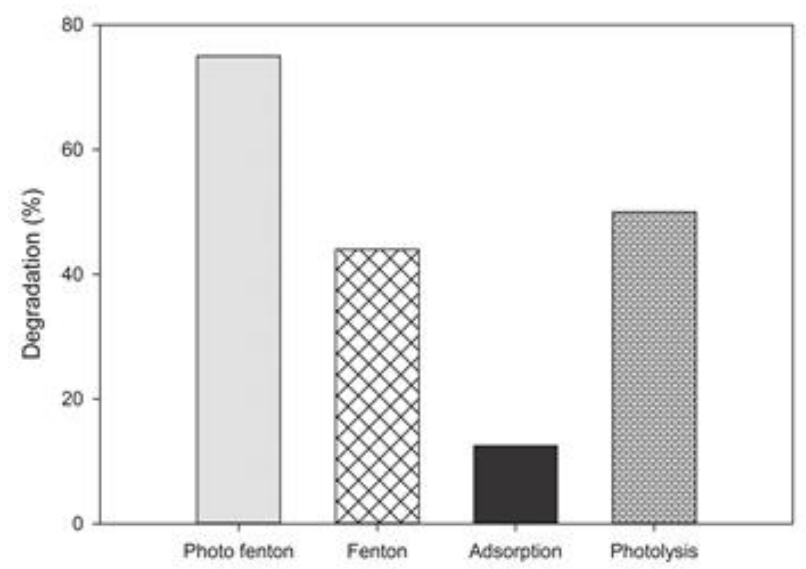

Fig 3:- Preliminary experiments of photo-Fenton, Fenton, adsorption and photolysis under identical experimental conditions at $\mathrm{MO}$ initial concentration $=5 \mathrm{mg} / \mathrm{L}, \mathrm{Fe}-\mathrm{Ac}$ dose $=1.0 \mathrm{~g} / 100 \mathrm{~mL}, \mathrm{pH}=3$ and $\mathrm{H}_{2} \mathrm{O}_{2}=1.0 \mathrm{~mL}$ for 30 minutes

\section{Modelling of Photo-Fenton Reaction}

In this study, a central composite design (CCD) was applied, because of simple models (linear, quadratic etc) can be related to response factor (percentage degradation). $\mathrm{CCD}$ is commonly used form of response surface methodology (RSM) [19].

Table 3 displays the sequential model sum of squares for all the possible models. The prob $>F$ value of $<0.0001$ for both Linear model and quadratic models suggests that both models are significant and could be used to study the photo Fenton reaction as values $<0.05$ are generally accepted. However, the model with highest order polynomial is most preferred [20]. Hence, the quadratic model is preferred. Other models with prob $>\mathrm{F}$ of above 0.05 are insignificant and thus disregarded in this analysis.

A model with maximum values of for both 'Adjusted R-squared' and 'Predicted R-squared' is recommended. Appendix I shows that quadratic model has Adjusted Rsquared' of 0.9901 and 'Predicted R-squared' of 0.9828 while maintaining a minimum standard deviation of 1.29 . With these model analyses, quadratic model is adopted for Analysis of Variance (ANOVA), diagnostics and model graphs analysis.

The second-order polynomial response equation was used to describe the interactions between dependent and independent variables. 
ISSN No:-2456-2165

\begin{tabular}{|c|c|c|c|c|c|c|}
\hline \multicolumn{9}{|c|}{ Lack of Fit Tests } \\
\hline Source & $\begin{array}{c}\text { Sum of } \\
\text { Squares }\end{array}$ & DF & $\begin{array}{c}\text { Mean } \\
\text { Square }\end{array}$ & $\begin{array}{c}\boldsymbol{F} \\
\text { Value }\end{array}$ & Prob $>\boldsymbol{F}$ & \\
\hline Linear & 2684.50 & 37 & 72.55 & 34.14 & $<0.0001$ & \\
\hline 2FI & 2672.50 & 27 & 98.98 & 46.58 & $<0.0001$ & \\
\hline Quadratic & 33.73 & 22 & 1.53 & 0.72 & 0.7397 & Suggested \\
\hline Cubic & 12.38 & 7 & 1.77 & 0.83 & 0.5926 & Aliased \\
\hline Pure Error & 14.88 & 7 & 2.13 & & & \\
\hline \hline
\end{tabular}

Table 4:- Lack of Fit Tests of the predicted models for photo-Fenton oxidation of MO using Fe-Ac

\footnotetext{
$Y=b_{0}+b_{1} A+b_{2} B+b_{3} C+b_{4} D+b_{5} E^{2}+b_{11} A^{2}+b_{22} B^{2}$ $+b_{33} C^{2}+b_{44} x D^{2}+b_{55} E^{2}+b_{12} A B+b_{13} A C+b_{14} A D+b_{15} A E$ $+b_{23} A C+b_{24} B D+b_{25} B E+b_{34} C D+b_{35} C E+b_{45} D E$
}

where, $Y$ is the \% MO dye removal, A,B,C,D and E represents the five independent variables $(\mathrm{pH}$, catalyst dose, hydrogen peroxide concentration, MO Initial dye concentration and time respectively), and the $b$ values represent regression coefficients.

Eight of the experiments were conducted at the central points. By using the Design Expert software, the following quadratic model for the experimental response was obtained (equation 1):

$\mathrm{Y}_{(\text {photo-Fenton })}=55.44-1.87 \mathrm{~A}+14.59 \mathrm{~B}+49.62 \mathrm{C}-2.74 \mathrm{D}$ $+0.89 \mathrm{E}-0.09 \mathrm{~A}^{2}-7.01 \mathrm{~B}^{2}-18.35 \mathrm{C}^{2}+0.07 \mathrm{D}^{2}-0.01 \mathrm{E}^{2}-$ $0.04 \mathrm{AB}+0.17 \mathrm{AC}+0.00 \mathrm{AD}-0.00 \mathrm{AE}-0.17 \mathrm{BC} 0.00 \mathrm{BD}+$ $0.02 \mathrm{BE}+0.05 \mathrm{CD}+0.00 \mathrm{CE}+0.00 \mathrm{DE}$

The coefficients of $\mathrm{E}^{2}, \mathrm{AD}, \mathrm{AE}, \mathrm{BD}, \mathrm{CE}$ and $\mathrm{DE}$ are insignificant and thus were neglected conveniently. The equation becomes

$\mathrm{Y}_{\text {(photo-Fenton) }}=55.44-1.87 \mathrm{~A}+14.59 \mathrm{~B}+49.62 \mathrm{C}-2.74 \mathrm{D}+$ $0.89 \mathrm{E}-0.09 \mathrm{~A}^{2}-7.01 \mathrm{~B}^{2}-18.35 \mathrm{C}^{2}+0.07 \mathrm{D}^{2}-0.04 \mathrm{AB}+$ $0.17 \mathrm{AC}-0.17 \mathrm{BC}+0.02 \mathrm{BE}$

According to equation (2) above, the weight of factor $\mathrm{A}(\mathrm{pH})$ on the equation is predominantly negative. There is decrease in $\mathrm{Y}$ for the variable $\mathrm{A}(-1.78)$, its second order component $\mathrm{A}^{2}(-0.09)$ and interactions with other parameter $\mathrm{AB}(-0.04)$, the results explains the apparent decrease in photo-Fenton response with increasing $\mathrm{pH}$.

There is an increase in $\mathrm{Y}$ for the factor $\mathrm{B}$ (catalyst dose) +14.59. However, its second order component $\mathrm{B}^{2}$ (7.01) is negative implying decrease in $\mathrm{Y}$ with increasing amount of B. It can be concluded that, there is an optimum value of $\mathrm{B}$ that yields maximum response $(\mathrm{Y})$.

The effect of parameter $\mathrm{C}\left(\mathrm{H}_{2} \mathrm{O}_{2}\right.$ dose $)$ iss silimar to that of $\mathrm{B}$ (Catalyst dose) above. Factor $\mathrm{C}(+49.62)$ is positive and its second order component $\left.C^{2} 18.35\right)$ is negative. The local value of $\mathrm{C}$ that yields maximum response (Y) is the optimum $\mathrm{H}_{2} \mathrm{O}_{2}$ dose.
Increase Parameter D (MO) Initial concentration (2.74) results in decrease in $Y$. its second order component $\mathrm{D}^{2}$ (0.07) increases the response with maximum $\mathrm{Y}$ obtainable at optimum value of $\mathrm{D}$

The effect of Factor $\mathrm{E}$ (Time) yields more response (Y) with increasing amount of time.

The ANOVA in this case confirms the adequacy of the quadratic model (the Model Prob $>F$ is $<0.0001$ which is substantially less than 0.05 .) The probability values for each individual term in the model can also be visualised. Independent variables of the quadratic model including $\mathrm{pH}(\mathrm{A})$, hydrogen peroxide concentration (C), MO concentration (D), time (E), and second order effects of catalyst dose $\left(\mathrm{B}^{2}\right)$, peroxide concentration $\left(\mathrm{C}^{2}\right)$, $\mathrm{MO}$ concentration $\left(\mathrm{D}^{2}\right)$, and Time $\left(\mathrm{E}^{2}\right)$ are significant with Prob $>F$ value of less than 0.05 . Moreover, first order effects of $(\mathrm{B})$ and interaction effects of $\mathrm{AB}, \mathrm{AC}, \mathrm{AD}, \mathrm{AE}, \mathrm{BC}, \mathrm{BD}$, $\mathrm{BE}, \mathrm{CD}, \mathrm{CE}$ and $\mathrm{DE}$ are insignificant with prob $>\mathrm{F}$ of above 0.05 .

Coefficient of determination $\left(R^{2}\right)$ is defined as the ratio of the explained variable to the total variation and a measure of the degree of fit. When $R^{2}$ is close to 1 , the model fits the actual experimental data better. The smaller the value of $R^{2}$, the less relevant the model fits the actual data [22-24]. Accordingly, for a good fit of a model, $R^{2}$ should be at least 0.80 . The $R^{2}$ value for variables is higher than 0.80 , which indicates that the regression model explains photo-Fenton the methyl orange degradation process by $\mathrm{Fe}-\mathrm{Ac}$ photocatalysis well. The $R^{2}$ value is 0.9941 (Table 4) for the degradation rate. The lack of fit value of 0.72 confirms the lack of fit is not significant relative to the pure error when $p$ value is $0.7395,>0.05$. The non-significant lack of fit shows good predictability of the model. The coefficient of variation $(\mathrm{C} . \mathrm{V} .=2.13)$ is low, indicated high precision and good reliability of the experimental values [25]. In addition, the " $R{ }^{2}$ Pred" of 0.983 is in reasonable agreement with the " $R$ " Adj" of 0.990 (within 0.2), which also implies good predictability of the model [26]. Adequate precision compares the range of predicted values at the design points to the average prediction error [27]. The adequate precision of 64.097 in this study, which is well above 4 indicates adequate model discrimination 
Three-dimensional surfaces and contour plots are graphical representation of regression equation for the optimization of process conditions, and very useful approach in revealing the conditions of the process.

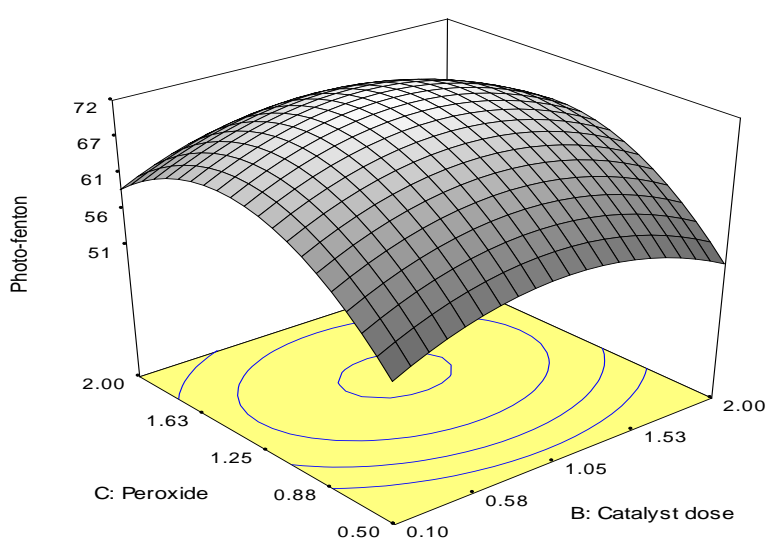

Fig 4:- Interaction plot of reaction parameters

Fig.4 shows the interaction effect of the main photoFenton reaction parameters: Catalyst dose ( $\mathrm{Y}$ axis) and $\mathrm{H}_{2} \mathrm{O}_{2}$ (X axis) on MO degradation rate (Abscissa). As can be seen in the plots, the interactions effects of catalyst dose and $\mathrm{H}_{2} \mathrm{O}_{2}$ concentration on the degradation rate of $\mathrm{MO}$ depict a spherical response surface; there is a local maximum region under the certain ranges catalyst dose and $\mathrm{H}_{2} \mathrm{O}_{2}$ concentration. In addition, there is an increase in the degradation rate of MO with an increase of upto about
$1 \mathrm{~g} / 100 \mathrm{~mL}$. This is attributed to the resultant increase in concentration of $\mathrm{Fe}^{2+}$ ions from additional catalyst. However, catalyst dose beyond the optimum level results in a decrease of MO degradation rate. This is due to the inherent cloudiness of the solution with addition of large amount of catalyst which reduces the amount of light penetrating the solution to produce hydroxyl radicals [21]. The decrease in degradation rate can also be attributed to scavenging of Hydroxyl radicals by the excess $\mathrm{Fe}^{2+}$ ions (equation 3).At the same time, the effect of hydrogen peroxide concentration change on the methyl orange degradation rate has similar trends. However, hydrogen peroxide concentration beyond the optimum level results in a detrimental decrease in methyl orange degradation rate. This can similarly be attributed to scanvenging of free Hydroxyl radicals by the excess hydrogen peroxide molecules (equation 3).

$\mathrm{Fe}(\mathrm{II})+\mathrm{OH} \rightarrow \mathrm{Fe}(\mathrm{III})+\mathrm{OH}^{-}$

$\mathrm{H}_{2} \mathrm{O}_{2}+\mathrm{OH} \rightarrow \mathrm{HO}_{2}+\mathrm{H}_{2} \mathrm{O}$

D. Optimization of photo-Fenton oxidation of MO using Fe-Ac catalyst

The objective of the optimization is to determine the optimum value of variables from the model obtained via experimental design and analysis. The previous works tend to concentrate on how to maximize the target product, and ignore some aspects of consideration with respect to reaction conditions, such as economic cost, ecological factor, subsequent treatment, etc [28].

\begin{tabular}{|c|c|c|c|c|c|c|c|c|}
\hline Number & $\mathrm{pH}$ & Catalyst dose & Peroxide & MO dye concentration & Time & \multicolumn{2}{|c|}{ Photo-Fenton } & \multicolumn{2}{|c|}{ Desirability } \\
\hline $\mathbf{1}$ & 3 & 0.1 & 0.62 & 5 & 30 & 76.31 & 0.955 & Selected \\
\hline $\mathbf{2}$ & 3.02 & 0.1 & 0.54 & 5.03 & 29.71 & 73.59 & 0.954 & \\
\hline $\mathbf{3}$ & 3.43 & 0.1 & 0.7 & 5 & 30 & 77.13 & 0.947 & \\
\hline $\mathbf{4}$ & 3 & 0.1 & 0.5 & 5.01 & 28.66 & 72.66 & 0.943 & \\
\hline $\mathbf{5}$ & 3.54 & 0.18 & 0.57 & 5.54 & 30 & 73.34 & 0.940 & \\
\hline $\mathbf{6}$ & 5.61 & 0.1 & 0.6 & 5 & 30 & 68.78 & 0.920 & \\
\hline $\mathbf{7}$ & 3 & 0.1 & 0.64 & 10.25 & 30 & 68.22 & 0.909 & \\
\hline $\mathbf{8}$ & 7 & 0.11 & 0.78 & 5 & 30 & 69.66 & 0.892 & \\
\hline $\mathbf{9}$ & 3 & 0.1 & 0.61 & 20 & 29.99 & 60.98 & 0.868 & \\
\hline $\mathbf{1 0}$ & 6.96 & 0.1 & 0.83 & 20 & 30 & 56.16 & 0.798 & \\
\hline
\end{tabular}

Table 5:- Results of Optimum parameters

Therefore, in present work, the higher degradation rate of methyl orange not only is obtained from optimization, but also some special conditions of $\mathrm{pH}$ value, catalyst dose, hydrogen peroxide concentration and methyl orange initial concentration also are considered at the same time. While, there are four aspects of considerations. First, the maximum degradation of methyl orange which is the main objective of optimization. Second, the optimal level of $\mathrm{pH}$ value should be as high as possible because of no readjustment after degradation process, the solution could be discharged directly to aquatic environment after removal of catalyst. Third, the relative small amount of catalyst has an advantage of subsequent treatment. Last, minimal amount of hydrogen peroxide should be required. Based on the quadratic model and the related constraint conditions (Maximizing $\mathrm{Y}$ while varying all the other parameters within experimental range, numerical optimization was carried out. The optimum conditions for the maximum MO degradation under related constraint conditions were found to be $\mathrm{pH}$ value of 3.00 , catalyst dose of $0.1 \mathrm{~g} / 100 \mathrm{ml}, \mathrm{H}_{2} \mathrm{O}_{2}$ dose of $0.62 \mathrm{ml}$, and $\mathrm{MO}$ initial concentration of $5.0 \mathrm{mg} / \mathrm{L}$ and for 30 minutes. Under optimal conditions, the model predicted a maximum methyl orange degradation rate of $76.3 \%$ (Table 5). These results imply that there exist optimal reaction conditions for degradation rate of methyl orange using Fe-Ac catalyst. 


\section{CONCLUSION}

In this research, we successfully demonstrated an effective way of degrading methyl orange azo dye in aqueous solution by employing photo-fenton reaction. The chemical reaction is dictated by several factors viz: reaction time, $\mathrm{Fe}$-Ac catalyst dose, methyl orange concentration, $\mathrm{pH}$ and $\mathrm{H}_{2} \mathrm{O}_{2}$ concentration. We further employed statistical tools embedded in central composite design to model the effect of these factors on the degradation reaction and obtain conditions for optimal degradation. The optimal conditions are as follows: $\mathrm{pH}=3$, catalyst dose $=0.1 \mathrm{mg} / 100 \mathrm{ml}, \mathrm{H}_{2} \mathrm{O}_{2}$ $=0.62 \mathrm{ml}$, methyl orange concentration $=5 \mathrm{mg} / \mathrm{l}$ and time $=$ 30 minutes.

\section{REFERENCES}

[1]. M. Lazar, S. Varghesec, and S. Nair, "Photocatalytic water treatment by titanium dioxide: recent updates," Catalysis, vol. 2, pp. 572-601, 2012.

[2]. C. Gilmour, "Water treatment using advanced oxidation processes: Application perspectives," Unpublished.

[3]. J.G. Carriazo, E. Guelou, J. Barrault, J.M. Tatibou, and S. Moreno, "Catalytic wet peroxide oxidation of phenol over Al- $\mathrm{Cu}$ or Al-Fe modified clays," Applied Clay Science, vol. 22, pp. 303-308, 2003

[4]. J. Kumar, and A. Bansal, "Immobilization of nanoparticles of titanium dioxide for photocatalytic degradation," Proceedings of the International Conference on Future Trends in Structural, Civil, Environmental and Mechanical Engineering. Bangkok, pp. 89-93, July 2013.

[5]. J.W. Shi, "Preparation of Fe(III) and Ho(III) co-doped $\mathrm{TiO}_{2}$ films loaded on activated carbon fibers and their photocatalytic activities," Chemical Engineering Journal, vol. 151, pp. 241-246, 2009.

[6]. F. Lucking, H. Koser, M. Jank, and A. Rilter, "Iron powder, graphite and activated carbon as catalysts for the oxidation of 4-chlorophenol with Hydrogen Peroxide in aqueous solution," Water Research, vol. 32, pp. 2607-2614, 1998.

[7]. J. Tokarsky, L. Neuwirthov'a, and P. Peikertov, "Polyaniline/ $\mathrm{TiO}_{2} /$ kaolinite: the composite material with high electrical anisotropy," Materials Chemistry and Physics, vol. 146, pp. 146-152, 2014.

[8]. G.A. Umbuzeiro, D.A Roubicek, C.M. Rech, M.I.Z. Sato, and L.D. Claxton, "Investigating the sources of the mutagenic activity found in a river using the Salmonella assay and different water extraction procedures," Chemosphere, vol. 54, pp. 1589-1597, 2004.

[9]. D.P. Oliveira, “ Dyes as important class of environmental contaminants - a case study. Corantes como importante classe de contaminantes ambientais - um estudo de caso," unpublished.

[10]. Lise, H.H, "Non priority analysis of the wastewater streams of four dye manufacturing facilities," Journal of the Water Pollution Control Federation, vol. 62, pp. 665-669, 2002.
[11]. R.J. Maguire, and R.J. Tkacz, "Occurrence of dyes in the Yamaska River, Quebec," Water Pollution Research, vol. 26, pp. 145-161, 1991.

[12]. G.A. Umbuzeiro, H. Freeman, S.H. Warren, F. Kummrow, and L.D. Claxton, "Mutagenicity evaluation of the commercial product C.I. Disperse Blue 291 using different protocols of the Salmonella assay," Food and Chemistry Toxicology, vol. 43, pp. 49-56, 2005.

[13]. I. Fatimah, I, Sumarlan, and T. Alawiyah, "Fe(III) $/ \mathrm{TiO}_{2}-$ Montmorillonite Photocatalyst in PhotoFenton-Like Degradation of Methylene Blue," International Journal of Chemical Engineering, vol. 1, pp. 1-9, 2015.

[14]. B. Kavitha, and D.T. Sarala, "Physico-chemical characterization of Activated carbon from Mullai," Journal of Applied Chemistry, vol. 50, pp. 54-56, 2014.

[15]. O.A. Ekpete, and H.J. Horsfall, "Preparation and characterization of activated carbon derived from fluted pumpkin stem waste," Journal of Chemical Science, vol. 1, pp. 10-17, 2011.

[16]. P.T. Almazan-Sanchez, and M.J. Solache-Rios, "Adsorption-regeneration by heterogeneous Fenton process using modified carbon and clay materials for removal of indigo blue," Environ Technol, vol. 37, pp. 1843-1856, 2016.

[17]. A.V. Edwin, "Surface Modification of Activated Carbon for Enhancement of Nickel (II) Adsorption," Journal of Chemistry, vol. 5, pp. 814-819, 2008.

[18]. E. Chamarro, A. Marco, and S. Esplugas, "Use of Fenton reagent to improve organic chemical biodegradability," Water Research, vol. 35, pp. 1047 1051, 2001.

[19]. A.R. Khtaee, M. Zarei, and S.K. Asl, "Photocatalytic treatment of a dye solution using immobilized

$\mathrm{TiO}_{2}$ nanoparticles combined with photoelectroFenton process: Optimization of operational parameters," Journal of Electroanal Chemistry, vol. 648, pp. 143-150, 2010.

[20]. D. Mansooreh, S. Esmaeel, F. Mahdi, and R.S. Mohammad, "Optimizing photo-Fenton like process for the removal of diesel fuel from the aqueous phase," Journal of Environmental Health Science and Engineering, vol. 12, pp. 87, 2014.

[21]. J. Kiwi, A. Lopez, and V. Nadtochenko, "Mechanism and Kinetics of the $\mathrm{OH}$ Radical Intervention during Fenton Oxidation in the presence of a significant

Amount of radical Scavenger," Environ. Sci. Technol, vol. 34, pp. 2162-2168, 2000.

[22]. R. Larson, and B. Farbar, Elementary Statisticspicturing the World. Beijing, China: Pearson Education Asia Limited and Tsinghua University Press, 2003.

[23]. J.M. Utts, and R.F. Heckard, Mind on Statistics. Thomson Learning in Asia and China. Machine Press, Beinjing: Mind of Statistics, 2002.

[24]. A.M. Joglekar, and A.T. May, "Product excellence through design of experiments," Cereal Food World, vol. 32, pp. 857-868, 1987. 
[25]. M. Amini, H. Younesi, N. Bahramifar, A.A.Z. Lorestani, F. Ghorbani, A. Daneshi, and M. Sharifzadeh, "Application of response surface methodology for optimization of lead biosorption in an aqueous solution by Aspergillus niger," Journal of Hazard. Material, vol. 154, pp. 694-702, 2008.

[26]. S. Ray, J.A. Lalman, and N. Biswas, "Using the BoxBenkhen technique to statistically model phenol photocatalytic degradation by titanium dioxide nanoparticles," Chemical Engineering Journal, vol. 150, pp. 15-24, 2009.

[27]. M.Y. Noordin, V.C. Venkatesh, S. Sharif, S. Elting, and A. Abdullah, "Application of response surface methodology in describing the performance of coated carbide tools when turning AISI 1045 steel," J. Mater. Process. Technol, vol. 145, pp. 46-58, 2004.

[28]. N. Nakada, K. Kiri, H. Shinohara, A. Harada, K. Kuroda, and S. Takizawa, " Evaluation of pharmaceuticals and personal care products as watersoluble molecular markers of sewage," Environmental Science and Technology, vol. 42, pp. 6347-6353, 2008 